S. Bloc ${ }^{1}$, C. Naudin², M. Merzoug ${ }^{2}$, P. Peillon ${ }^{1}$, J.M. De Gournay ${ }^{1}$, F. Pamela ${ }^{1}$, X. Sala Blanch ${ }^{3}$, P. Squara ${ }^{2}$

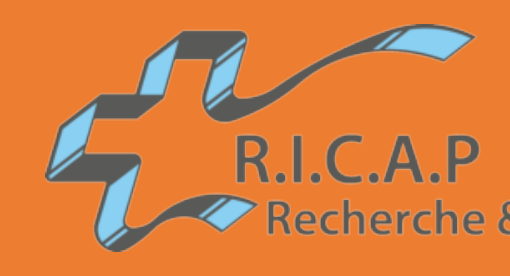

\section{BACKGROUD AND AIMS}

Sciatic nerve block (SNB) is the standard for foot surgery, providing good anaesthesia and long duration of analgesia. However, the proximal sciatic block results in a motor blockage of the ankle, making walking difficult.

Distal block of the sciatic nerve (tibial and fibular nerve blocks) (TNPB), at the level of the ankle, has been proposed to maintain the mobility of the ankle, to make deambulation with crutches easier. Nevertheless, the lack of sensibility of the heel could remains a limitation for early walking.

A specific anesthesia of the distal part of the foot, respecting the heel, could be a good option to provide an early deambulation and a suitable analgesia.

This study was designed to assess the feasibility of a specific block of the tibial nerve plantar branches.

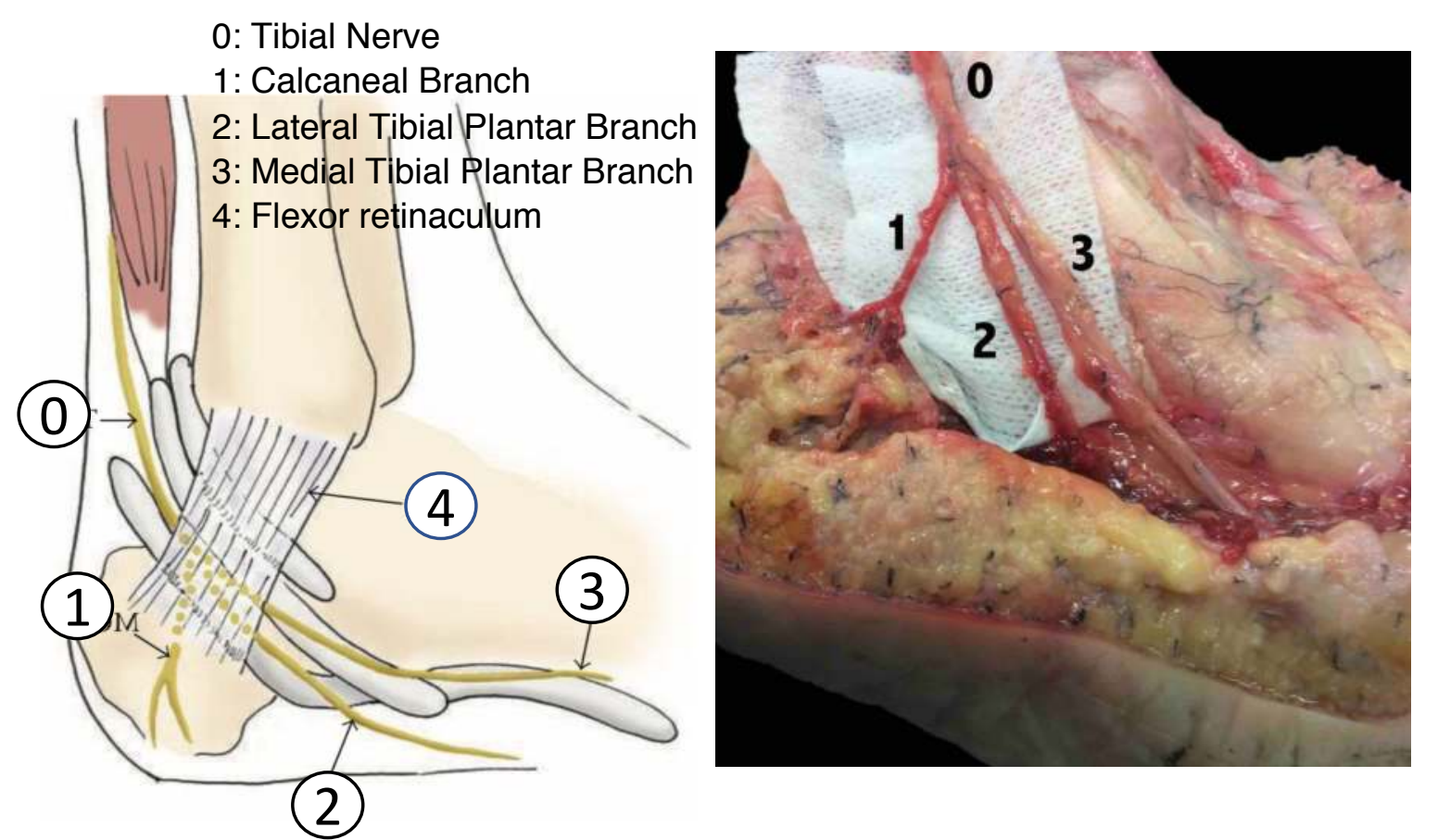

Figure 1: Tibial nerve course and divisions (X. Sala-Blanch)

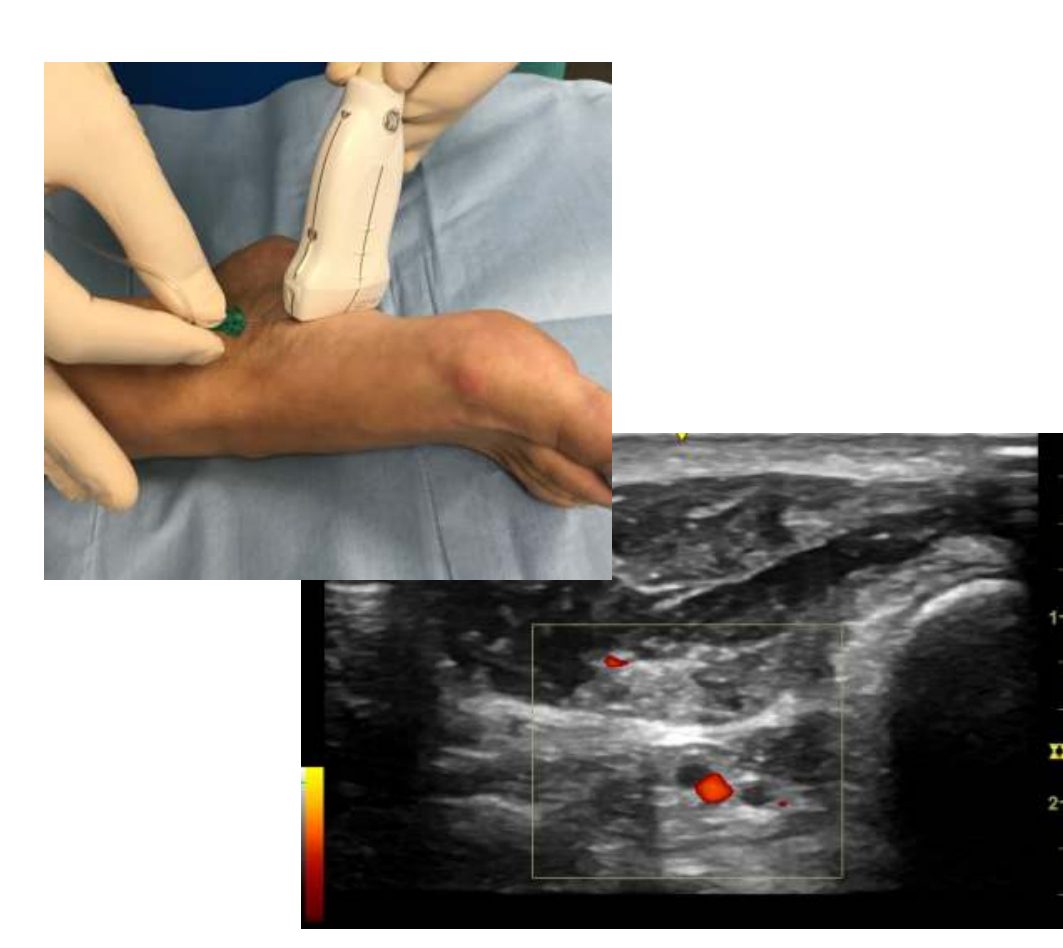

Figure 2: Tibial plantar branches block performance

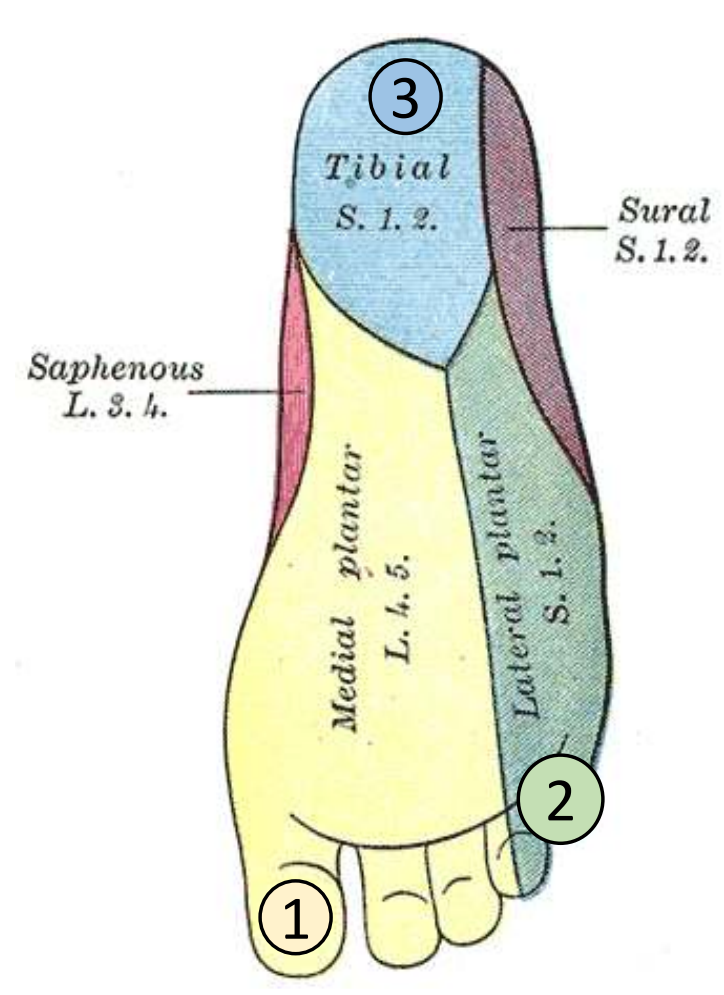

Figure 3: Area of Isolated Supply

\section{METHODS}

25 patients, ASA I-III scheduled for foot surgery were included.

Each block was performed under ultrasound with 5-7 $\mathrm{ml}$ of $0.375 \%$ Ropivacaine including block of peroneal nerves and block of medial and lateral plantar branches (Figure 2).

Block efficiency was assessed by pinprick and cold tests in the specific sensory territory of the 3 branches (Figure 3) :

- Medial Tibial Plantar Branch (1)

- Lateral Tibial Plantar Branch (2)

- Calcaneal Branch (3)

\title{
RESULTS
}

\section{Surgical anaesthesia $\mathbf{4 0}$ minutes after TNPB (Figure 4)}

Medial plantar nerve area : $100 \%$

Lateral plantar nerve area : 12\% [0\% ; 24\%]

Additional anaesthesia : 8 patients

- 5 SNB

- 3 general anaesthesia

\section{5 sedation for comfort}

Heel sensibility In the postoperative period (Figure 5) 95\% [85\%; 100\%]
20 min post TNPB
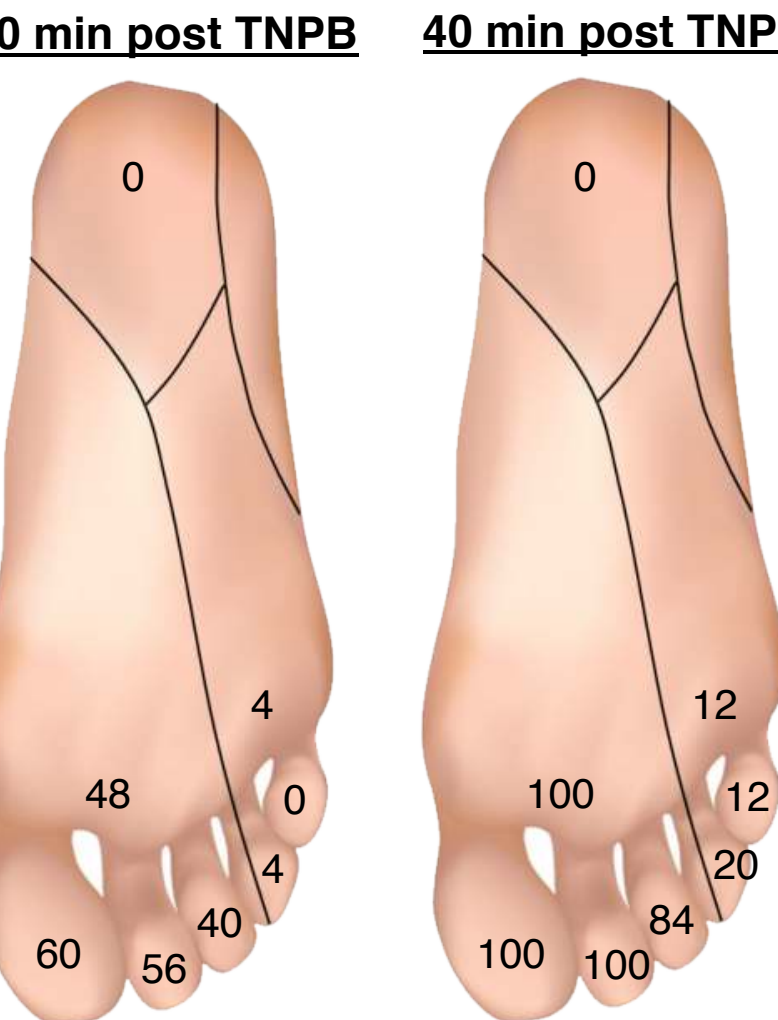

Figure 4 : Surgical anaesthesia Data are presented as percentages

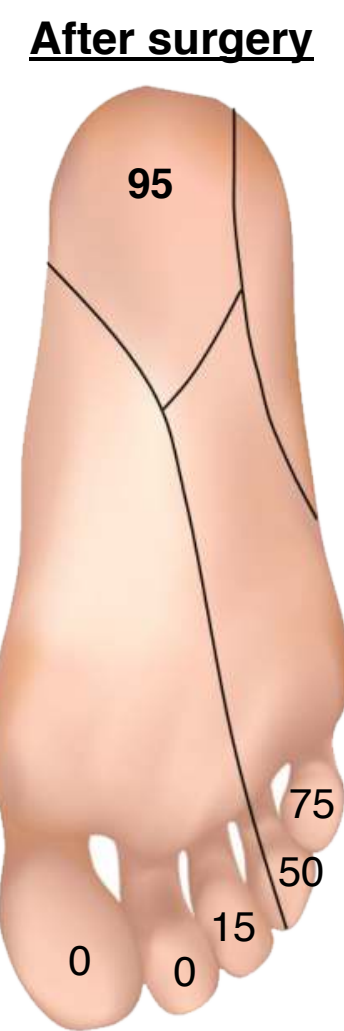

Figure 5: Sensibility Data are presented as percentages

\section{CONCLUSIONS}

A specific block of TNPB is possible at the medial edge of the foot. It makes it possible to respect the calcaneal branch, thus maintaining the sensitivity of the heel. While the medial branch block is systematic, efficiency on the lateral branch is inconstant. A more proximal approach or the use of a larger volume of anaesthetic should be considered. 